\title{
Uso de volumosos conservados na alimentação de equinos
}

\begin{abstract}
José Luiz Domingues ${ }^{1}$
${ }^{1}$ Engenheiro Agrônomo. Prof. Dr., Consultor Autônomo - SP.

RESUMO - Revisão de artigos sobre características e uso de forragens conservadas na alimentação de equinos, considerando o bem estar animal e ressaltando a necessidade de integrar a atual tecnologia do uso, fisiologia, manejo e nutrição animal. Um ponto básico e critico no manejo alimentar de equinos é a disponibilidade de forragens de alta qualidade para uso como pastagens, ou forragens conservadas na forma de fenos e silagens. Os mais tecnificados sistemas de produção animal adotaram o feno para alimentação e este é o motivo pelo qual grande parte dos artigos científicos relativos à nutrição de equinos usou o feno como volumoso. Silagens são adotadas em alguns sistemas, porém poucos artigos técnicos estão disponíveis avaliando seu uso na nutrição de equinos. Devido às características anatômicas e fisiológicas, o equino deve receber grandes quantidades de forragem e a taxa de fornecimento deve permitir a seletividade da captura e fácil ingestão da forragem. Para qualquer volumoso, o perfil nutricional deste é diferente quando oferecido na forma de pastagem ou forragem conservada, situação atribuída a seletividade e individualidade animal bem como a variação nas partes da planta. Paralelamente com o conhecimento da composição nutricional e manejo de conservação de forragem, especial atenção deve ser dada as condições ambientais de alojamento e restrição de movimentos dos animais. O planejamento de atividade física para o equino conjuntamente com o manejo adequado ajuda a prevenir problemas que afetam animais que não tem acesso a pastagem. Os fenos, silagens e pré-secados, usados quando a pastagem não é disponível, divide com o concentrado o maior número de casos de problemas de saúde. Cólica, acidose, laminite, consumo de palha e madeira estão associados a deficiências nutricionais, desconsiderando erros humanos e condições ambientais desapropriadas. Informações técnicas para melhor entendimento sobre o consumo animal em qualidade, quantidade e/ou a forma que o alimento é fornecido, vem sendo responsável pelo desempenho positivo e bom manejo de equinos mantidos em sistemas que o privam de acesso a pastos e atividades físicas.
\end{abstract}

Palavras-chave: equinos, forragem conservada, feno, manejo, nutrição, silagem

\section{Use of conserved roughage in the horse feeding}

\begin{abstract}
This text revised some papers in literature about characteristics and use of conserved forages for horse feeding, considering animal behavior and outstanding the need of programs that could integrate the current knowledge of use, physiology, management and animal nutrition. A basic and critical nutritional condition for equine management is the availability of high quality forage for use as pasture or conserved as hay or silage. Most professional horse production systems adopt hay for animal feeding and this is why most available scientific papers regarding horse nutrition uses hay as roughage. Silages are adopted in some systems, but a smaller number of studies are available in technical literature evaluating his use in horse nutrition. Due to their anatomic and physiological characteristics, horses should be given high quality pastures and stocking rates must allow selectivity in forage capture and easy ingestion. For any forage, the nutritional profile is different if offered to animals used as pasture or conserved, due selectivity, plants part and variation among horses. Besides the analytical results of feeds and conservation processes adopted, special attention should be given to the environmental conditions of animal kept in stables or with restricted movements. A physical activity plan for horses and adherence to appropriate routines help preventing problems that affect animals without access to pasture. The hays, silages and haylages used as substitutes when pasture is not available, share with concentrates the highest position as causes of health problems. Colic, acidosis, laminitis, straw and wood consumption are associated to nutritional deficiencies, without considering human mistakes and inappropriate environmental conditions. Technical information for better understanding of animal consumption in quality, quantity or the way food is offered, has been responsible for the positive performance and good management in systems that deprive their access to pastures or physical activities.
\end{abstract}

Key Words: conserved forages, hay, horse, management, nutrition, silage 


\section{Introdução}

A produção de forragens de alta qualidade, tendo a sua utilização na forma de pastagens ou sendo conservada através de processos como fenação ou ensilagem, é uma condição básica e crucial na produção de equinos. A boa qualidade presente nas pastagens e nas forragens conservadas permite um manejo animal equilibrado, com suprimento de nutrientes de boa qualidade e com maior estabilidade durante todo o ano.

Pela seleção que sofreram e pela presença das adaptações anatômicas e fisiológicas que apresentam atualmente, os equinos são animais que deveriam sempre ter sua criação e utilização em condições que permitissem sua permanência em pastagens, com boa qualidade e oferta de forragem adequada ao número de animais. Isso permite que eles possam exercer sua seletividade na coleta e ingestão das forragens, de acordo com a palatabilidade e da situação de oferta e qualidade de cada espécie forrageira, em função da fertilidade do solo e clima. Além dos aspectos físicos, as condições de manejo dos animais mantidos com acesso a pastagens afetam as características comportamentais desses animais, exercendo grande influência sobre a eficiência dos criatórios, nos resultados obtidos nos locais de trabalho e de utilização e principalmente na qualidade de vida dos animais.

Os processos de conservação de forragens podem ser utilizados nos sistemas de produção onde a oferta de volumosos é maior que seu consumo. O excedente da produção de forragens pode ser aproveitado antes que se torne excessivamente maduro e tenha perdas nessa qualidade. As alternativas mais utilizadas para conservação de forragens além das pastagens são a produção de fenos, silagens e pré-secados.

Com uso crescente de dietas completas, visando facilitar o fornecimento de energia, proteína e fibras, o maior entendimento dos efeitos da variação no consumo diário de volumosos e concentrados assume um papel importante na nutrição de equinos. Essas variações causam mudanças significativas no ecossistema gastrintestinal, podendo levar a alterações na digestibilidade das dietas e a consequências fisiológicas traumáticas nos animais (Miraglia et al., 2006).

\section{Hábitos dos animais e coleta de forragem}

Embora os estudos procurem avaliar a qualidade das diferentes espécies forrageiras, sejam elas manejadas de diferentes formas, épocas do ano, adubações, tipos de solos ou sob diferentes alturas de corte, o consumo de pastagens por equinos é bastante peculiar, fazendo com que uma grande parte dessas informações não possa ser diretamente utilizada no manejo animal sem que sejam avaliados também a forma de apreensão e os dados de consumo efetivo dessas forrageiras.

A qualidade nutricional e física da forragem oferecida aos animais sob forma conservada é muito diferente daquela obtida em condições ótimas de pastejo, onde os animais podem exercer livremente sua seletividade (Dittrich et al., 2007). Essa constatação alcança seu ponto mais interessante, em termos de comportamento ingestivo, quando nos deparamos com condições de estabulação com ausência ou redução significativa de atividade física.

Lamoot et al. (2004) relataram que, da mesma forma que outros herbívoros, os cavalos podem utilizar pastagens desuniformes para seu pastejo, despendendo mais tempo de pastejo em pastos mais baixos. Outro comportamento marcante ocorre em pastagens onde há a presença de áreas definidas para deposição das fezes, chamadas de "latrinas", que são evitadas para o consumo da forragem ali presente. Esse comportamento alimentar altamente seletivo de cavalos em pastagens, tem sido interpretado há tempo como uma estratégia de controle de endoparasitas.

Fleurance et al. (2005) concluíram que a seletividade de forragem pelos cavalos em pastejo é mais influenciada pela qualidade nutricional dessa forragem do que pela presença de fezes e parasitas nessa pastagem. Destacam que a preferência de consumo recai em pastagens que oferecem melhores estandes e com maiores benefícios nutricionais, a despeito dos riscos parasitários ali presentes. Nas condições do experimento realizado, a seleção de forragens nutritivas superou a seleção por forragens sem riscos parasitários. A expectativa de que cavalos evitariam pastagens contaminadas com fezes foi confirmada apenas para as de menor altura e com menor disponibilidade forragem de qualidade, onde o benefício nutricional das áreas com e sem contaminação foi o mesmo. Assim, animais com histórico de presença de parasitas correriam mais riscos para obter benefícios nutricionais do que os não parasitados.

Segundo Zeiner et al. (2004), comportamentos impróprios durante as refeições como nervosismo, agressividade e inquietação, da mesma forma que frequente coprofagia, estão relacionados respectivamente a dietas com muito concentrado (amido) e pouco volumoso. Isso pode explicar o fato de muitos animais estabulados e com algum tipo de deficiência nutricional apresentarem consumo de cama de baia ou restos de forragem no piso, mas fica a dúvida se os mesmos teriam a capacidade de tentar suprir a sua demanda nutricional consumindo resíduos que ainda apresentariam boa qualidade. 
Para analisar a qualidade dos volumosos e mesmo do material usado para cama, Wichert et al. (2008), analisaram a qualidade dos materiais fibrosos (fenos, pré-secados, silagens e palhas usadas como cama de baias), comparando suas qualidades tácteis, visuais e olfativas com os valores de lipopolissacarídeos (LPS) presentes nesses volumosos. Os teores de LPS correlacionaram-se negativamente ao tempo de secagem dos fenos e positivamente com a contagem microbiológica dos alimentos. Os autores destacaram que essas análises podem ser feitas para avaliar a qualidade higiênica dos alimentos e mostrar a exposição total de um determinado alimento a microrganismos grampositivos. Observaram que o cuidado com a aquisição dos alimentos não se repete para a qualidade das camas. Este material apresentou menor qualidade higiênica, sendo apontado como uma fonte potencial de problemas respiratórios nos animais estabulados.

De acordo com Zeyner et al. (2004), uma alimentação rica em amido representa risco de problemas nutricionais, como lesões na superfície da mucosa intestinal ou síndromes como cólicas ou laminite. Comportamentos anormais ou estereotipados como coprofagia ou mastigação de madeira estão sempre relacionados a dietas com alto consumo de amido e não relacionadas em dietas exclusivas com fenos, que podem atenuar os problemas com amido. Ao mesmo tempo em que diminui a densidade energética das dietas, o uso de níveis elevados de alimentos fibrosos aumenta o consumo de água em relação a dietas com menores níveis, fazendo com que a oferta e a qualidade da água tenha maior importância nesses sistemas de produção. Para Miraglia et al. (2006), o aumento na população de microrganismos amilolíticos, associados ao aumento do lactato e acidose intestinal, determina a redução da população de bactérias celulolíticas e redução na digestibilidade da fração fibrosa.

\section{Uso e consumo de silagens}

Em sua recente revisão sobre os métodos para avaliação da qualidade de forragens conservadas, Jobim et al. (2007), destacam a importância do uso de tecnologias para esse fim e apresentam tecnologias em uso ou em desenvolvimento para avaliação da qualidade dos alimentos volumosos e das possíveis perdas durante o processo de produção e no armazenamento. Para uso do conceito de "forragem de qualidade", afirmam que para determinação do valor nutritivo de uma forragem, sempre devem ser consideradas em conjunto as características físicas e bromatológicas dos alimentos, bem como a interação entre seu consumo pelo animal e o desempenho em produção desse mesmo animal. Em relação a silagens, os autores apresentam uma série de metodologias e equipamentos, mas para as forragens desidratadas, basicamente os fenos, observam poucos avanços metodológicos relativos à avaliação da sua qualidade, constatando serem raros os trabalhos com avaliação das alterações em qualidade ocorridas durante o processo.

As silagens de diferentes espécies vegetais e os présecados, principalmente de gramíneas, embora sejam usadas em países da Europa, são pouco utilizados nas dietas de equinos no Brasil. O trabalho de Hanche-Olsen et al. (2008) mostra que em 27 propriedades avaliadas na Noruega, 25 delas ( $>90 \%$ ) usavam silagem como volumoso. A s circunstâncias mais frequentes observadas de utilização de silagens para alimentação de equinos no Brasil são aquelas onde os animais de trabalho permanecem por algum tempo próximos aos cochos de bovinos alimentados com esse material, há poucos trabalhos que utilizaram silagem de milho, capim-elefante ou sorgo como base de volumosos para dietas de equinos. Isso se deve principalmente à necessidade de manutenção de estrutura física e equipamentos específicos, da baixa densidade em matéria seca das silagens e dos problemas de manejo das mesmas para a manutenção de sua qualidade e palatabilidade, tanto antes como depois da abertura dos silos.

Algumas observações sobre o uso de silagens usando espécies do gênero Cynodon são apresentadas por Evangelista \& Lima (1999). Os autores destacamque o ideal seria produzir feno ou utilizar essa espécie para pastejo. A produção de silagem apenas seria válida como estratégia de manejo de campos de feno, se as condições climáticas não permitissem a execução do processo de fenação.

O uso de silagens para equinos ainda levanta suspeita como causadoras potenciais de problemas neurológicos, pelo fato de estarem erradamente associadas a uma presença constante de fungos e contaminação por micotoxinas.

Ricketts et al. (1984), ressaltaram a presença potencialmente grave de bactérias em silagens conservadas sob condições inadequadas em silos plásticos. Condições de fermentação não apropriadas das forragens, não proporcionam um controle ambiental adequado para prevenir o desenvolvimento de bactérias do gênero Clostridium, possibilitando assim a presença de suas toxinas nos silos.

Casos de fraqueza simétrica nos extensores digitais presentes na musculatura de equinos ocorridos na Noruega e com causa desconhecida, levaram os pesquisadores Hanche-Olsen et al. (2008) a um levantamento de campo e avaliação de animais buscando explorar algumas hipóteses. Os achados clínicos mostraram tratar-se de uma polineuropatia envolvendo degeneração neuronal. Como 
os dados epidemiológicos e os resultados de laboratório não mostraram causas infecciosas e por destacarem que a única condição existente em comum nos diferentes casos era o uso de silagem ou feno com pobre qualidade microbiológica, sugeriram uma causa ligada possivelmente a fatores nutricionais. Os autores afirmaram que os sinais neurológicos nos animais avaliados não corresponderam aos sinais causados por micotoxinas e não realizaram análises para esses metabólitos nas dietas. Entretanto, muitos artigos de divulgação sobre equinos, publicados em revistas técnicas não científicas, citaram esse trabalho colocando a silagem e o pré-secado como causadores de micotoxicoses nos animais.

Ainda são escassas as informações sobre micotoxicoses em equinos e não estão claros os efeitos aditivos ou sinergísticos da associação de duas ou mais toxinas em um alimento (Hanche-Olsen et al., 2008). Os autores sugerem a realização de trabalhos nessa área, considerando-a como um desafio importante que forneceria informações de como fornecer silagem aos equinos de maneira segura.

\section{Uso e consumo de fenos}

O feno é uma forma de conservação de forragens que facilita o manuseio desse alimento volumoso, tem presença constante e disponibilidade no mercado físico e apresenta um bom valor nutritivo quando bem elaborado e armazenado. As atividades de manejo do feno adquirido ou produzido na propriedade devem sempre ter em vista a qualidade nutricional, a segurança alimentar e o bem estar animal.

As técnicas de fenação são conhecidas e descritas há bastante tempo e vem sendo avaliadas para a maioria das espécies forrageiras. Para Reis et al. (2001), além da espécie e idade das plantas forrageiras, os principais fatores para obtenção de um produto de alta qualidade são: o manejo de corte, que visa uma desidratação adequada e o conhecimento técnico para superar os condicionantes apresentados pelos fatores ambientais. Esses fatores interferem diretamente na qualidade bromatológica e sanitária dos fenos, bem como nas perdas no processo produção.

Muck \& Shinners (2001) relataram que o feno é uma das formas de conservação de forragem mais utilizadas em todo o mundo, principalmente nos locais onde as condições de secagem são favorecidas. Além das características nutricionais, a presença de um mercado com boa oferta, a facilidade no transporte devido a sua baixa densidade e o armazenamento em condições ambiente, fazem com que a adoção de fenos seja um fato definitivo na produção de equinos.

Existem perdas consideráveis em qualidade e quantidade dos fenos, mesmo quando todos os condicionantes para uma produção adequada estão sendo atendidos. Assim, aqueles autores indicam a necessidade de pesquisas em: a) compreender os processos que afetam a qualidade dos fenos durante a produção e o armazenamento; b) desenvolver meios práticos para reduzir as perdas e aumentar qualidade. Pode ser adicionado a essas observações o cuidado com o manejo alimentar dos animais. Ações incorretas ou negligentes podem fazer com que rações ou fenos percam sua qualidade original em função de um manejo nutricional inadequado.

O manejo nutricional deve considerar quantidades, horários e sequencia para o fornecimento das refeições em função do uso e intensidade de exercício dos animais. Considerando estes aspectos, muitos técnicos consideram desejável a redução na velocidade de ingestão de concentrados pelos equinos.

A influência da origem e qualidade do alimento fibroso sobre as características da digestão do amido e as respostas em insulina e glucose sanguíneas não estão bem definidas para equinos. Vervuert et al. (2008), descrevem eventos fisiológicos ligados à digestão de concentrados associados ao consumo de volumosos, bem como os efeitos da ordem em que estes alimentos são oferecidos e consideram prática generalizada a adição de alimentos fibrosos aos concentrados como forma de aumentar o tempo de consumo e a produção de saliva. Esta atua como tamponante no estômago, afeta positivamente a digestão, dilui o quimo e facilita sua acidificação e taxa de passagem para o intestino delgado. Um fluxo de passagem mais uniforme do estômago ao intestino está associado a uma menor incidência de úlceras gástricas.

Os autores comentam a adição de alimentos fibrosos às refeições, tanto antes como em mistura às dietas ricas em amido. Essa prática pode ser desvantajosa quando usado feno de gramíneas, pois parece reduzir a digestibilidade do amido em pôneis, diminuindo a resposta glicêmica dos animais com a adição de feno. Esse efeito foi atribuído a um aumento na taxa de passagem do cereal pelo intestino delgado, bem como à diluição de enzimas pelo aumento das secreções digestivas. $\mathrm{O}$ aumento na taxa de passagem de cereais pelo intestino delgado requer atenção, uma vez que o amido não digerido pode sofrer fermentação bacteriana.

O resultado apresentado para a adição de alfafa, tanto antes, como depois ou junto às refeições com aveia mostra, ao contrário das gramíneas, que não houve efeito sobre a digestão pré-cecal do amido, melhorou a digestão deste no intestino delgado e diminuiu a fermentação bacteriana.

A qualidade dos fenos utilizados na produção de equinos pode ser avaliada a partir de diferentes aspectos, que devem ser considerados sempre em conjunto, visando 
um melhor entendimento na utilização dessa matéria prima. Os principais aspectos a considerar são ligados a fatores nutricionais, sanitários e operacionais.

A qualidade nutricional dos fenos em termos de energia e proteína, bem como as restrições relativas ao seu consumo devem ser cuidadosamente observadas. Um cavalo adulto com peso de $600 \mathrm{~kg}$ e consumindo cerca de 2 a $2,5 \%$ do seu peso corporal em matéria seca, ingere em média 6 a $7 \mathrm{~kg}$ de feno diariamente. Essa é uma quantidade significativa e que interfere diretamente na ingestão de diversos nutrientes. Uma dieta produzida com fenos de boa qualidade poderá suprir a demanda de animais adultos em manutenção ou pouca atividade.

Para a correta seleção visual do feno a fornecer aos equinos, deverão ser avaliadas algumas características e observados alguns cuidados, como os destacados por Haddad \& Domingues (1999), que entre os mais significativos destacam:

a) observar o conteúdo de vários fardos, avaliar com maior atenção e melhorar a eficiência dessa avaliação;

b) escolher fenos que tenham hastes finas, folhosos, macios ao tato e com coloração verde característica. Não se preocupar apenas com a coloração externa, pois uma leve descoloração pode ocorrer devido ao sol durante o armazenamento;

c) evitar fenos muito secos, excessivamente expostos ao sol, com cheiro de bolor, empoeirados ou fermentados;

d) selecionar aqueles que tenham sido cortados com a forrageira ainda não madura, antes do florescimento. Examinar para a presença de perfilhos reprodutivos e sementes;

e) evitar os fenos que contenham plantas tóxicas, plantas invasoras, sujidades e outros materiais estranhos;

f) examinar os fardos quanto à presença de insetos, aranhas e outros animais potencialmente problemáticos;

g) rejeitar os fardos excessivamente pesados em relação ao seu volume. Observar se estão quentes ao toque, pois podem conter umidade excessiva, levando ao aparecimento de fungos e podendo causar combustão espontânea nos fardos armazenados;

h) adquirir feno novo e usá-lo em seguida, para utilizar seu melhor valor nutricional;

i) manter os fardos em locais secos, longe do solo e das paredes, ventilados e livres da incidência de sol e das chuvas, onde possam ser vistoriados e retirados com facilidade;

j) identificar o lote adquirido ou produzido e avaliar o resultado das análises bromatológicas desse lote para conhecer seu verdadeiro valor nutricional.
A aparência externa de um feno, mesmo parecendo adequada, nunca deve ser um requisito único para a decisão sobre a qualidade ou classificação desse feno. Uma análise bromatológica realizada com protocolos de amostragem corretos e significativos para um determinado lote poderá mostrar seu valor nutricional comparativo aos padrões adotados. Análises como proteína bruta, fibra insolúvel em detergente neutro, fibra insolúvel em detergente ácido, nitrogênio ligado à fração fibrosa e concentração de minerais (cálcio, fósforo, potássio, magnésio) devem ser realizadas a fim de manter o controle da qualidade do alimento adquirido ou produzido. Tabelas com valores sugeridos para cada parâmetro de qualidade de fenos são apresentadas pelo NRC (2007) e por Carvalho et al. (1992).

Além dos problemas na manutenção da qualidade dos fardos, um problema potencial apresentado pelos fenos armazenados com alta umidade ou reumedecidos no armazenamento é a combustão espontânea. Os mecanismos e condições para ocorrência dessa combustão foram pesquisados e apresentados nos trabalhos de Miao \& Yoshizaki (1994) e Miao et al. (1994). No caso da combustão espontânea de fenos, a mudança na temperatura é determinada pelo balanço de calor. Calor é produzido a partir de reações químicas e perdido por evaporação da água. Os autores concluíram que o aumento nas taxas de produção de $\mathrm{CO}_{2}$ e $\mathrm{CO}$ foram expressas como funções lineares das taxas de aumento de temperatura durante a combustão. O aumento de temperatura do feno, causado por reações químicas em atmosfera úmida, se dá em dois estágios. O primeiro corresponde à absorção de umidade pelo feno seco até a umidade de equilíbrio. Nesse estágio inicia-se uma produção de calor a taxas elevadas, alcançando uma temperatura média de $97^{\circ} \mathrm{C}$. No segundo estágio, sob temperaturas médias de $120^{\circ} \mathrm{C}$, essa temperatura para de subir, em função das perdas por evaporação. Apenas após o feno estar suficientemente seco, a temperatura se eleva novamente, alcançando o ponto de ignição. Assim, as reações químicas e o aumento de temperatura são controlados pelo teor de umidade e suprimento de ar na massa enfardada.

A determinação da umidade em fenos pode ser feita com o auxílio de equipamentos com medidas de impedância dielétrica sob freqüência controlada. O coeficiente de determinação desse método, avaliado por Eubanks \& Birrel (2001), mostrou-se entre 0,74 e 0,95 para diferentes materiais, indicando boa precisão nas determinações, mas com necessidade de calibrações para cada espécie vegetal.

Da mesma forma que em qualquer outra determinação analítica, a amostragem apresenta-se como um dos pontos 
críticos para a representatividade dos lotes, da eficiência das medidas obtidas e da precisão dos valores encontrados.

O Conselho Americano de Forrageiras e Pastagens (AFGC, 2001, 2004), indica uma forma de organização da produção e implantação de parâmetros definidos de qualidade, para tentar manter os padrões nutricionais desse alimento presente no mercado. Entre os principais cuidados está a separação dos fenos em nove classes distintas e bem caracterizados, em função das espécies e da idade das forragens utilizadas na sua confecção. O julgamento baseiase nas análises bromatológicas e visuais, considerando vários itens com um peso para cada item: valor alimentar relativo (RFV, Relative Feed Value) 45\%, qualidade alimentar relativa (RFQ, Relative Feed Quality) $15 \%$, aparência física $25 \%$, proteína bruta $15 \%$, totalizando $100 \%$ da avaliação.

$\mathrm{O}$ valor alimentar relativo (RFV) baseia-se no conceito de consumo de matéria seca digestível (MSD) em relação a uma forrageira padrão, onde o consumo é estimado pela FDN e a matéria seca digerível pela FDA. O valor 1,29 é baseado no padrão de RFV da alfafa florescida.

$\mathrm{RFV}=$ (consumo matéria seca, em \% do peso corporal) * (MSD, \% da matéria seca) / 1,29

Pelas equações de predição desses parâmetros, podemos utilizar os valores das análises bromatológicas das frações fibrosas ADF e NDF, assim teríamos:

$\mathrm{RFV}=[(88,9-0,779 * \mathrm{ADF}) *(120 / \mathrm{NDF})] / 1,29$

Para a qualidade alimentar relativa (RFQ), foi usado o valor do NDT (nutrientes digestíveis totais) no lugar da matéria seca digerível, onde o fator 1,23 é usado para ajustar a equação buscando uma faixa similar a RFV.

$\mathrm{RFQ}=($ consumo matéria seca, \% peso corporal $) *(\mathrm{NDT}$, $\%$ da matéria seca)/ 1,23

A qualidade alimentar relativa (RFQ) foi adotado como um dos critérios de avaliação da qualidade das forragens com base em ensaios experimentais. O RFV ainda é o principal critério, pois seus valores proporcionam uma melhor indicação do desempenho animal para a maioria dos fenos.

A alteração na qualidade nutricional dos fenos, enfardados com alta umidade (acima de $200 \mathrm{~g} / \mathrm{kg}$ ) durante o período de armazenamento, foi descrita por Turner et al. (2002). Os autores observaram variações nas concentrações dos componentes fibrosos em feno de Cynodon dactylon, apresentando os modelos dessas variações.

Os autores verificaram que as concentrações dos componentes fibrosos, fibra insolúvel em detergente neutro (FDN) e fibra insolúvel em detergente ácido (FDA) aumentaram durante o período de armazenamento. Também ocorreram mudanças significativas nas frações do nitrogênio ligado à fibra, principalmente no nitrogênio insolúvel em detergente ácido (NIDA) e observaram que essas mudanças ocorreram com maior intensidade nos primeiros doze dias de armazenamento. Sob condições de alta umidade, além da elevação da temperatura e queda na disponibilidade de proteína, ocorreu o aparecimento de fungos nesses fenos, comprovando que todos os esforços devem tentar viabilizar uma desidratação correta do material antes do enfardamento.

Coblentz et al. (2000) também armazenaram fardos de feno de gramíneas sob diferentes densidades e concentrações de umidade, observando que as densidades tiveram pouco efeito sobre o valor nutricional e outras características dos fenos. Os resultados também indicaram que o nitrogênio em Cynodon dactylon é muito susceptível a reduções em sua disponibilidade biológica. Isso seria devido à elevação da temperatura durante o armazenamento, causada por atividade microbiológica. Esse dano aumentou à medida que se elevou a umidade ao enfardamento.

Produtores e pesquisadores buscam sistemas eficientes de condicionamento para aumentar as taxas de secagem a campo com uso de aditivos como ácido propiônico e sais de potássio, além de sistemas de secagem que possam manter uma boa qualidade dessa matéria prima. A necessidade de baixa umidade é menos rigorosa em fardos pequenos, devido sua menor densidade. Para fardos com maior densidade há necessidade de uma matéria seca maior (Coblentz et al., 2000).

Lascano et al. (2001) identificaram diversos fatores ambientais com influência marcante sobre a qualidade das forragens e dos fenos produzidos a partir delas. Condições de estresse ambiental são responsáveis por grande parte dessa variação na produção e na qualidade das forragens. O estresse ocorre quando um fator ambiental não é adequado ou é restritivo ao desenvolvimento vegetal normal, como seca, altas temperaturas, inundação, sombreamento e deficiências minerais. As conclusões dessa revisão mostram que a temperatura tem o efeito mais intenso sobre a digestibilidade das forragens, principalmente nas gramíneas, pelo seu efeito sobre a diminuição na relação folha: haste, aumentando as frações menos digestíveis. Os efeitos do sombreamento são mais presentes e variáveis sobre a produção e menos intensos sobre a qualidade. O efeito da seca é variável e geralmente pequeno sob condições não severas. $\mathrm{O}$ efeito dos nutrientes no solo tem se mostrado pouco relevante sobre a qualidade das forragens, mas com um efeito notável sobre a produção total e sobre o rendimento das diferentes espécies forrageiras. As exceções seriam o nitrogênio, cujo efeito sobre os teores de proteína bruta são 
consideráveis e o aporte de enxofre e cálcio em solos deficientes nesses minerais, onde podem melhorar a digestibilidade e a composição dos tecidos.

Entre os principais fatores ambientais que apresentam influência sobre a taxa de desidratação das forragens estão a intensidade da radiação solar, temperatura e umidade relativa do ar e umidade do solo. As chuvas são as principais causadoras de perdas em quantidade e qualidade na produção de fenos. (Rankin \& Undersander, 2004)

Entre os aspectos relacionados às operações mecânicas, destaca-se a ação e intensidade de condicionamento, bem como a densidade da massa e leiras de secagem. O corte realizado com segadora condicionadora permite regulagens na altura de corte, na força de prensagem dos rolos condicionadores e na largura e densidade da faixa de deposição do material cortado. Essa operação permite que o material possa ser mais bem distribuído sobre o solo, aumentando a insolação, ventilação e perda de umidade.

Os trabalhos realizados com essa técnica apresentaram resultados satisfatórios, com aumento nas taxas de secagem, no consume voluntário e na digestibilidade. Em alguns trabalhos a maceração causou perdas no consumo de matéria seca e na qualidade nutricional sob condições de umidade elevada (Savoie, 2004). Para esse autor, o aumento do valor nutritivo pela maceração pode ser explicado pela quebra mecânica das fibras e pela redução nas taxas de respiração celular e proteólise quando a secagem é realizada juntamente a outros fatores que proporcionam uma secagem rápida. As reduções em qualidade observadas após a maceração devem-se principalmente ao aumento da respiração e perdas por fragmentação excessiva, quando a secagem se realiza demoradamente ou fica sujeita a chuvas. A implantação da maceração junto às demais etapas do processo de fenação depende da adoção de mecanismos que proporcionem ao mesmo tempo simplicidade, baixo custo de operação e manutenção e aumento nas taxas de secagem e no valor nutricional.

Tratamentos com diferentes produtos químicos podem ser utilizados para aumentar a velocidade de secagem no processo. Soluções de carbonato de potássio e carbonato de sódio são as mais comumente utilizadas e estudadas. Outras substâncias como aditivos químicos ou biológicos também podem proporcionar vantagens para a conservação de fenos. Ácido propiônico tem apresentado resultados positivos na preservação de fenos com maior concentração de umidade, prevenindo crescimento de microrganismos e evitando perdas de folhas.

A amônia anidra também tem características e propriedades para a preservação eficiente de fenos, mas pelos riscos potenciais à saúde humana, tem sido pouco indicado. Inoculantes microbianos tem sido apresentados para conservação de silagens e de fenos, contendo estirpes de lactobacilos e enzimas. Há poucas indicações positivas da eficiência de seu uso no Brasil.

Secadores são adotados como meio auxiliar nos processos de secagem sob condições favoráveis de umidade relativa do ar ou como método exclusivo de secagem sob condições adversas de clima. Seu uso favorece a padronização e manutenção do controle de qualidade dos fenos (Rotz \& Chen, 1985).

O uso de secadores artificiais é uma das alternativas mais interessantes do ponto de vista de qualidade e manejo das culturas para a produção de fenos. Embora caros, muitos produtores de alfafa no Brasil utilizaram esses equipamentos a fim de superar as restrições ambientais e obter maior qualidade nos fenos.

Seu uso está condicionado pela demanda do mercado e pelo preço diferenciado e sua produção condicionada pelos custos diretos e dependência de mão-de-obra treinada para os serviços e controles necessários. Destacam-se os controles de temperatura e tempo de secagem, visando evitar os danos causados pelo superaquecimento, como perda de folhas e diminuição na digestibilidade.

Nascimento et al. (2000), estudaram a influência de seis métodos de fenação. Os autores verificaram que os fenos onde a forrageira ficou mais tempo exposta ao sol apresentaram pior qualidade em PB, FDN e FDA. Tal fato foi explicado pela diminuição da relação folha:haste com o emurchecimento ao sol. No tratamento secagem ao sol a relação folha: haste $(0,46)$ representou $41 \%$ daquela do material original $(1,12)$. O método mais adequado para a conservação da alfafa consistiu na exposição da forragem ao sol até a perda de $50 \%$ do peso da forragem original, com posterior secagem do material espalhado à sombra.

Segundo Hlodversson \& Kaspersson (1986), ocorreu acentuada alteração na população de fungos com o processo de fenação, havendo diminuição dos gêneros típicos de campo, como Fusarium e Cladosporium, e aumento de Aspergillus e Penicillium de maior ocorrência no armazenamento. Os fungos de armazenamento, como o Aspergillus, normalmente se desenvolvem em fenos com maior conteúdo de umidade, podendo servir como indicador biológico das condições de armazenamento.

Em revisão sobre a ocorrência de micotoxinas em silagens, Scudamore \& Livesey (1998), citam que sob condições adversas de produção e armazenamento, podem ocorrer perdas de matéria seca pela presença de fungos contaminantes. Entretanto, como a microbiota fúngica dos 
volumosos difere significativamente da presente nos cereais, caso ocorra contaminação por micotoxinas, essa deverá ser diferente em quantidade e qualidade. Para os autores, fenos elaborados sob boas condições, apresentam uma microflora limitada e equilibrada, resultante da sucessão de diferentes espécies nas diferentes etapas de produção, sendo: fungos de campo (pré-colheita), fungos intermediários (colheita) e fungos de armazenamento (póscolheita). Os fungos de armazenamento são mais diversos em condições de alta umidade.

Nascimento et al. (2000), com trabalho sob condições ambientais no Brasil, avaliaram a influência de seis métodos de fenação e sua relação sobre a incidência de fungos em feno de alfafa. Verificaram diferenças significativas entre os métodos de secagem e mostraram que a ocorrência de fungos foi maior nos tratamentos em que a forragem não sofreu emurchecimento e naqueles em que foi amontoada. A maior incidência de fungos no início do armazenamento deveu-se à presença de gêneros típicos de campo, que tendem a desaparecer, com consequente mudança nas populações de fungos durante $o$ armazenamento.

Comparando dados de composição, os autores verificaram que a ocorrência de fungos não influenciou a composição bromatológica dos fenos, porém seu aspecto geral foi depreciado, com mudanças na coloração pela presença de esporos.

Segundo Yianniouris \& Jouany (2002), os equinos são mais susceptíveis aos danos por micotoxicoses que os ruminantes. Os níveis considerados tóxicos para equinos são: aflatoxinas (50 ppb), toxina T-2 (50 ppb), deoxinivalenol (400 ppb), zearalenona (100 ppb), fumonisina (2000 ppb). Esses níveis são baseados em observações de campo, sendo necessários estudos para esclarecer a tolerância às diferentes toxinas e seus efeitos tóxicos (Jones et al., 1994). Para Newman \& Raymond (2005), ainda não são conhecidos os efeitos da associação de várias micotoxinas nas dietas de equinos. Segundo Rotter et al. (1996), a presença do deoxinivalenol (DON) ou vomitoxina, é sempre vista como um indicador da ocorrência de outras micotoxinas, pois ele consegue manter-se estável mesmo após secagem, aquecimento ou moagem.

Segundo Jones et al. (1994), as forragens mofadas seriam menos palatáveis e haveria uma recusa e diminuição no consumo voluntário desses fenos pelos equinos, levando à diminuição na ingestão das toxinas, caso presentes. Assim, a ingestão de princípios toxigênicos poderia ser controlada antes de causar algum dano, o que não ocorre no caso de contaminação de grãos. A susceptibilidade às micotoxicoses pode ser aumentada pela presença de várias toxinas, estresse, nutrição inadequada, superlotação, exposição a doenças e interações de medicamentos, entre outros fatores.

Wanjun et al. (1999), analisaram amostras de fenos e silagens e identificaram várias micotoxinas, sendo que todas as amostras dos fenos analisados apresentavam concentrações menores que 1,0 ppm. Os autores destacam a necessidade de uso de metodologias adequadas de amostragem e de análise para cada matéria prima. Para Jones et al., (1994), em função da não existência de pesquisas conclusivas a respeito desses níveis para equinos, devem ser fornecidos alimentos isentos de micotoxinas.

No Brasil os fenos e forragens apresentam uma participação reduzida no total de análises para presença de micotoxinas, com menos de $6 \%$ das amostras, sendo que menos de $0,5 \%$ estariam contaminadas (Gonçalez et al., 2001).

Em termos de qualidade operacional, a padronização das operações de corte, secagem e enfardamento das forragens interfere diretamente nas transformações a que essas forragens estarão sujeitas durante o período de armazenamento. Em função da homogeneidade da umidade da massa no processo de secagem, do teor de matéria seca ao enfardamento, da densidade imposta aos fardos e do tipo de fardo e forma de armazenamento, essas variações serão significantes, em maior ou menor grau, para a qualidade nutricional final dos fenos (Bonilha, 1994).

Além dos controles da secagem para obtenção de umidade segura, a necessidade de controles operacionais mais estreitos é muito clara para qualquer nutricionista que já teve oportunidade de acompanhar o desembarque de uma carga de feno. A dispersão de partículas de poeira e solo pelo ambiente, perda de folhas, fardos desamarrados ou soltos e variação no tamanho e peso dos fardos são as ocorrências mais freqüentes.

Para as atividades ligadas à produção de volumosos, a produção de informações técnicas ainda é relativamente escassa, bem como a aplicação de ações corretivas nos processos. Como possíveis causas de variação de peso entre fardos produzidos em uma mesma área foram indicados: a heterogeneidade da produção dentro das áreas, a falta de dimensionamento operacional, restrições na operação de revolvimento da forragem, leiras de forragem com densidade desuniforme e limitações dos equipamentos.

Muck \& Shinners (2001), apresentaram revisão da pesquisa e desenvolvimento de novos equipamentos para fenação, principalmente no que diz respeito às inovações e adaptações para aumento de produtividade desses 
equipamentos, bem como evoluções buscando novos sistemas de amarração, corte, aumento da densidade e formatos de fardos. Para os autores, não deve haver preocupação demasiada com o tipo de enfardadora usado, pois a tarefa mais fundamental na produção de fenos em condições de clima úmido é assegurar uma desidratação adequada para propiciar uma estabilidade no material durante o armazenamento.

Pesquisas para medição e controle das diversas operações agrícolas vêem sendo desenvolvidas nas operações de fenação, tanto para umidade dos fardos como para quantificação e padronização da produção. Foram avaliados sensores de fluxo de massa em equipamentos de fenação (Shinners et al., 2002, 2003), quando o desenvolvimento de sistemas de mapeamento por produtividade pode ser capaz de mostrar diferenças espaciais na produção relacionadas à altitude, tipo de solo, padrões de tráfego e de fertilidade. Os mapas obtidos a partir de sensores de fluxo de massa podem se tornar uma ferramenta valiosa na agricultura de precisão e de qualidade.

Uso e consumo de pré-secados

Pré-secados são forragens conservadas obtidas por um processo intermediário à fenação e ensilagem, baseado na secagem parcial das forragens e na sua fermentação por microrganismos sob condições anaeróbicas. As silagens são obtidas principalmente de culturas ricas em grãos e apresentam matéria seca entre 30 e $45 \%$, sendo preservadas por acidez, resultante principalmente da ação de bactérias láticas que proporciona um $\mathrm{pH}$ entre 3,5 e 4,5. Os présecados apresentam menor acidez e umidade, com matéria seca entre 50 a $60 \%$, apresentando maiores teores de proteína e vitaminas que os fenos pelo fato de serem cortados em estágio vegetativo mais jovem e ficarem menos tempo expostos ao sol que os fenos (Frape, 2004).

Embora os pré-secados apresentem fatores dietéticos positivos e sejam uma alternativa técnica muito interessante para local onde a taxa de secagem é comprometida, há ainda algumas limitações para seu maior uso e difusão. Entre eles está o grande volume dos atuais fardos ou sacolas de armazenamento, que dificulta o transporte e o manejo de abertura dos mesmos quando há um número pequeno de animais a alimentar. Também a avaliação desse material deve considerar a qualidade microbiológica dos mesmos. $\mathrm{O}$ manejo dos pré-secados deve evitar presença de bolores ou bactérias causadores de fermentações indesejadas, uma vez que alta umidade e baixa acidez favorecem o desenvolvimento de fungos toxigênicos ou mesmo de Clostridium.

\section{Considerações Gerais}

$\mathrm{Na}$ produção de equinos ainda há uma carência de informações técnicas e uma presença bem maior de preconceitos do que em outras espécies. Isso pode ocorrer tanto pela escassez de trabalhos pesquisa e pela não divulgação do conhecimento existente, quanto pelo aumento no número de pessoas que interagem com cavalos e que ignoram os conceitos fisiológicos e nutricionais mais básicos desses animais.

Embora os requerimentos nutricionais do equinos estejam estabelecidos em termos de proteína, energia, vitaminas e minerais, Jackson (1996) afirma existir uma grande variação nessa demanda em função de características individuais e para cada uso de animal, concluindo que diferentes animais podem ganhar ou perder peso quando alimentados seguindo essas recomendações. Como exemplo, Vervuert et al. (2005) citam a baixa repetibilidade nos experimentos com equinos, em termos de resposta às mesmas dietas sob condições experimentais idênticas. Os resultados dos trabalhos experimentais apresentam grande variabilidade também em função dos altos custos nas pesquisas de campo, das dificuldades no manejo de animais mais temperamentais e da baixa sobrevivência nos procedimentos cirúrgicos mais invasivos com equinos,

As pesquisas sobre as formas de conservação e uso dos alimentos volumososdevem buscar maior precisão nos seus resultados pelo aumento no número de animais experimentais, pela melhoria na seleção dos indivíduos e pela padronização eficiente das condições ambientais, usando os parâmetros técnicos mais adequados para avaliar os efeitos dos tratamentos e metodologias que possam ressaltar as diferenças entre eles.

Em relação ao uso de novas fontes de alimentos fibrosos, Miraglia et al. (2008) mostram que pode haver uma redução na digestibilidade da fibra quando ela tem origem em subprodutos como polpa cítrica ou de maçã. Assim, o uso de dietas mistas ricas em fibra dietética ou os chamados "concentrados dietéticos", deve ser bem analisado antes de sua difusão. Uma redução no amido por refeição poderia trazer mais eficiência do que o uso de novas fontes de fibra, bastando aumentar o número de refeições.

O uso de volumosos conservados na nutrição de equinos, seja na forma de fenos, pré-secados ou silagens, deve sempre compreender a fisiologia, a presença de uma ativa microflora intestinal e as características de consumo desses animais, considerando no estabelecimento do manejo a sua anatomia peculiar e as necessidades atávicas de atividade física e relacionamento grupal. 


\section{Literatura Citada}

AFGC. American Forage and Grassland Council. A Report on America's Forage and Grassland Resources and Needs Stewardship for the 21st Century. March, 2001. Disponível em http://www.afgc.org/pujr001aa.html. Acesso em 30/05/ 2008.

AFGC. American Forage and Grassland Council. 2004 National Hay Show - Rules and Regulations. Disponível em http:// www.afgc.org/cohs001.html. Acesso em 30/05/2008.

BONILHA, J.A. Qualidade total na agricultura: fundamentos e aplicações. Belo Horizonte: CEQTA. 1994. 344p.

CARVALHO, R.T.L.; HADDAD, C.M.; DOMINGUES, J.L. Alimentos e alimentação do cavalo. Piracicaba: LC. Consultores Associados. 1992. 130 p.

COBLENTZ, W.K.; TURNER, J.E.; SCARBROUGH, D.A. et al. Storage characteristics and nutritive value changes in bermudagrass hay as affected by moisture content and density of rectangular bales. Crop Science, v.40, p.1375-1383, 2000.

DITTRICH, J.R.; CARVALHO, P.C.F.; MORAES, A. et al. Comportamento ingestivo de equinos em pastejo sob diferentes dosséis. Ciência Animal Brasileira, v. 8, n.1, p.87-94, 2007.

EUBANKS, J.C.; BIRRELL, S.J. Determining moisture content of hay and forages using multiple frequency parallel plate capacitors. Paper 011072, 2001 ASAE Annual Meeting. Disponível em: 〈http://asae.frymulti.com/newresults.asp.> Acesso em: 30/5/2008.

EVANGELISTA, A.R; LIMA, J.A. [1999]. Silagem de espécies do gênero Cynodon. Lavras: UFLA, Boletim Técnico, 86. Disponível em: http://www.editoraufla.br/BolExtensao/pdfBE/ bol_86.pdf. Acesso em: 10/1/2009.

FLEURANCE, G; DUNCAN, P.; FRITZ, H. ET AL. Importance of nutritional and anti-parasite strategies in the foraging decisions of horses: an experimental test. Oikos, v.110, p.602612, 2005.

FRAPE, D. Equine nutrition e feeding. 3.ed. Victoria: Blackwell Publishing, 2004. 650p.

GONÇALEZ, E.; PINTO, M.M.; FELÍ́CIO, J.D. Análise de micotoxinas no Instituto Biológico de 1989 a 1999. O Biológico, v.63, n.1/2, p.15-19, 2001.

HADDAD, C.M.; DOMINGUES, J.L. Como avaliar fenos de qualidade. Revista Pecuária de Corte, v.10, n. 90, p.56-60, 1999.

HLODVERSSON, R.; KASPERSSON, A. Nutrient losses during deterioration of hay in relation to changes in biochemical composition and microbial growth. Animal Feed Science and Technology, v.15, n.2, p.149-165. 1986.

HANCHE-OLSEN, S.; TEIGE, J.; SKAAR, I. et al. Polyneuropathy associated with forage sources in norwegian horses. Journal Veterinary Internal Medicine, v.22, n.1, p.178-184, 2008.

JACKSON, S.G. Feeding and nutrition of the performance horse. Equine neurology and nutrition. In: Bain-Fallon Memorial Lectures, 8., 1996, Glenelg. Proceedings... Australia, July 1996. p.151-161. Disponível em: http://www.scielo.br. Acesso em: $10 / 01 / 2009$.

JOBIM, C.C.; NUSSIO, L.G; REIS, R.A. et al. Avanços metodológicos na avaliação da qualidade da forragem conservada. Revista Brasileira de Zootecnia, v.36, supl., 2007.

JONES, F.T. et al. Understanding and coping with effects of mycotoxins in livestock feed and forage. North Carolina Cooperative Extension Service. Electronic Publication Number DRO-29, Dec.1994. Disponível em: http://www.ces.ncsu.edu/ disaster/drought/dro-29.html. Acesso em: 30/05/2008.

LAMOOT, I.; CALLEBAUT, J.; DEGEZELLE, T. et al. Eliminative behavior of free-ranging horses: do they show latrine behaviour or do they defecate where they graze? Applied Animal Behavior Science, v.86, p.105-121. 2004.

LASCANO, C.E.; SCHIDT, A.; BARAHONA, R. Forage quality and the environment. In: INTERNATIONAL GRASSLAND CONGRESS, 19., 2001, Sâo Pedro. Anais... São Pedro: SBZ. 2001. (CD-ROM).

MIAO, Y.; YOSHIZAKI, S. Mechanism of spontaneous heating of hay. 1. Necessary conditions and heat generation from chemical reactions. Transactions of ASAE, v.37, n.5, p.1561-66. 1994.

MIAO, Y.; AMARI, M.; YOSHIZAKI, S. Mechanism of spontaneous heating of hay. 2. Chemical changes in spontaneously heated hay. Transactions of ASAE, v.37, n.5, p.1567-70, 1994.

MIRAGLIA, N.; BERGERO, D.; POLIDORI, M. et al. The effects of a new fibre-rich concentrate on the digestibility of horse rations. Livestock Science, v.100, n.1, p.10-13, 2006.

MIRAGLIA, N.; POLIDORI, M.; BERGERO, D. et al. Apparent digestibility of a dietetic feed in equine nutrition. Journal of Food, Agriculture \& Environment, v.6, n.2, p.295-298, 2008.

MUCK R.E.; SHINNERS, K.J. Conserved forage (silage and hay): progress and priorities. In: INTERNATIONAL GRASSLAND CONGRESS, 19., 2001, Sâo Pedro. Anais... São Pedro: SBZ. 2001. (CD-ROM).

NASCIMENTO, J.M.; COSTA, C.; SILVEIRA, A.C. et al. Influência do método de fenação e tempo de armazenamento sobre a composição bromatológica e ocorrência de fungos no feno de alfafa (Medicago sativa, L. cv. Flórida 77). Revista Brasileira de Zootecnia, v.29, n.3, p.669-677, 2000.

NEWMAN, K.E.; RAYMOND, S.L. Effects of mycotoxins in horses. In: DIAZ, D. (Ed.). The mycotoxin blue book. Nottingham: Nottingham University Press, 2005. p.57-76.

NATIONAL RESEARCH COUNCIL - NRC. Nutrient requirement tables. Nutrient Requirements of Horses. 2007. 6.ed. Disponível em: http://www.nap.edu. Acesso em 30/01/ 2009.

RANKIN, M.; UNDERSANDER, D. [2004]. Rain damage to forage during hay and silage making. Disponível em http:/ /www.cce.cornell.edu/ scnyag/dairy/newsletter. Acesso em: $30 / 5 / 2008$.

REIS, R.A.; MOREIRA, A.L.; PEDREIRA, M.S. Técnicas para produção e conservação de fenos de forrageiras de alta qualidade. In: SIMPÓSIO SOBRE PRODUÇÃO E UTILIZAÇÃO DE FORRAGENS CONSERVADAS, 2001, Maringá. Anais... Maringá : UEM/CCA/DZO, 2001. 319p.

RICKETTS, S.W.; GREET, T.R.; GLYN, P.J. et al. Thirteen cases of botulism in horses fed big bale silage. Equine Veterinary Journal, v.16, n.6, p.515-8, 1984.

ROTTER, B.A.; PRELUSKY, D.B.; PESTKA, J.J. Toxicology of deoxynivalenol (vomitoxin). Journal of Toxicology and Environmental Health, v.48, p.1-34, 1996.

ROTZ, C.A.; CHEN, Y. Alfalfa drying model for the field environment. Transactions of the ASAE, v.28, n.5, p.1686$1891,1985$.

SAVOIE, P. [2003]. Forage maceration: past, present and future. Disponível em: http://asae.frymulti.com. Acesso em: 30/05/ 2008.

SCUDAMORE, K.A.; LIVESEY, C.T. Occurrence and significance of mycotoxins in forage crops and silage: a review. Journal of the Science of Food and Agriculture, v.77, n.1, p.1-17. 1998.

SHINNERS, K.J. [2002]. Getting the most from the mowerconditioner. Disponível em: <http://www.uwex.edu/ ces/forage/ wfc/proceedings. Acesso em: 30/5/2008.

SHINNERS, K.J.; HUENINK, B.N.; BEHRINGER, C.B. [2003]. Precision agriculture as applied to North American hay and forage production. Disponível em: <http:// asae.frymulti.com.> Acesso em: 30/5/2008.

TURNER, J.E.; COBLENTZ, W.K.; SCARBROUGH, D.A. et al. Changes in nutritive value of bermudagrass hay during storage. Agronomy Journal, v.94, p.109-117, 2002.

VERVUERT, I.; VOIGT, K.; HOLLANDS, T. et al. [2005]. The effect of mixing and changing the order of feeding oats and chopped alfalfa to horses on: glycaemic and insulinaemic 
responses, and breath hydrogen and methane production. Journal of Animal Physiology and Animal Nutrition. Disponível em: <http://www3.interscience.wiley.com/journal/ 121376647/abstract.> Acesso em: 25/1/2009.

VERVUERT, I.; KLEIN, S.; COENEN, M.[2008]. Effect of mixing dietary fiber (purified lignocellulose or purified pectin) and a corn meal on glucose and insulin responses in healthy horses. Journal of Animal Physiology and Animal Nutrition. Disponível em: <http://www3.interscience.wiley.com/ journal/ 121376647/ abstract.> Acesso em: 25/1/2009.

WANJUN, Y.; FENG-YIH, Y.; D.J. UNDERSANDER, D.J. et al. Immunoassays of selected mycotoxins in hay, silage and mixed feed food and agricultural. Immunology, v.11, n.4, 1999, p.3079. Disponível em: 〈http://taylorandfrancis.metapress.com.>
Acesso em: 30/5/2008

WICHERT, B.; NATER, S.; WITTENBRINK, M.M. et al. Judgement of hygienic quality of roughage in horse stables in Switzerland. Journal of Animal Physiology and Animal Nutrition, v.92, p.432-437, 2008.

YIANNIKOURIS, A.; JOUANY, J.P. Les mycotoxines dans les aliments des ruminants, leur devenir et leurs effets chez l'animal. Production Animal, v. 15,p.3-16, 2002. Disponível em http:/ /www.inra.fr/Internet/ Produits. Acesso em: 30/5/2008.

ZEYNER, A.; GEIßLER, C.; DITTRICH, A. Effects of hay intake and feeding sequence on variables in faeces and faecal water (dry matter, pH value, organic acids, ammonia, buffering capacity) of horses. Journal of Animal Physiology and Animal Nutrition, v.88, p.7-19. 2004. 